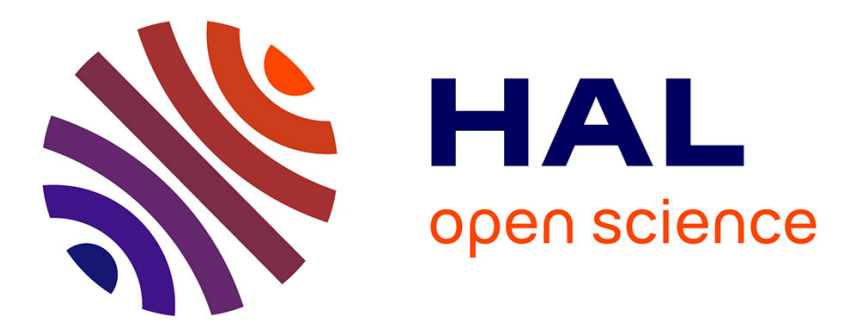

\title{
Effect of a horizontal magnetic field on convective instabilities in mercury
}

S. Fauve, C. Laroche, A. Libchaber

\section{To cite this version:}

S. Fauve, C. Laroche, A. Libchaber. Effect of a horizontal magnetic field on convective instabilities in mercury. Journal de Physique Lettres, 1981, 42 (21), pp.455-457. 10.1051/jphyslet:019810042021045500 . jpa-00231972

\section{HAL Id: jpa-00231972 https://hal.science/jpa-00231972}

Submitted on 1 Jan 1981

HAL is a multi-disciplinary open access archive for the deposit and dissemination of scientific research documents, whether they are published or not. The documents may come from teaching and research institutions in France or abroad, or from public or private research centers.
L'archive ouverte pluridisciplinaire HAL, est destinée au dépôt et à la diffusion de documents scientifiques de niveau recherche, publiés ou non, émanant des établissements d'enseignement et de recherche français ou étrangers, des laboratoires publics ou privés. 


\title{
LE JOURNAL DE PHYSIQUE-LETTRES
}

\section{Effect of a horizontal magnetic field on convective instabilities in mercury}

\author{
S. Fauve, C. Laroche and A. Libchaber \\ Groupe de Physique des Solides de l'Ecole Normale Supérieure (*), 24, rue Lhomond, 75231 Paris Cedex 05, France
}

(Reçu le 3 août 1981, accepté le 4 septembre 1981)

\begin{abstract}
Résumé. - Nous étudions l'effet d'un champ magnétique horizontal sur les instabilités tridimensionnelles se produisant dans une expérience de Rayleigh-Bénard avec le mercure. L'effet d'un champ magnétique parallèle à l'axe des rouleaux convectifs est d'inhiber l'instabilité oscillatoire de Busse et de maintenir le fluide dans un état convectif bidimensionnel, auquel est associé un transport de chaleur élevé, qui pourrait correspondre à un mode de convection inertiel.
\end{abstract}

\begin{abstract}
The effect of a horizontal magnetic field on the three-dimensional instabilities which occur in a Rayleigh-Bénard experiment with mercury is studied. When the magnetic field is parallel to the roll axis, the Busse oscillatory instability is inhibited, and the fluid motions become bidimensional. The high heat transport may be associated with an inertial convection mode.
\end{abstract}

We report here some new results on the effect of an externally impressed magnetic field on the dynamical instabilities which occur in a Rayleigh-Bénard experiment in mercury, a low Prandtl number fluid. (The Prandtl number is $P=v / K$, where $v$ is the kinematic viscosity, and $K$ the thermal diffusivity; for mercury at room temperature, $P=0.025$.) It is known from the studies of Chandrasekhar that a magnetic field induces a tendency towards two-dimensionality of convective motions [1]. A horizontal uniform magnetic field, applied along the convective roll axis, does not influence the steady bidimensional motions, but inhibits three-dimensional disturbances. We have recently studied the three-dimensional instabilities, using a low aspect ratio cell of mercury heated from below, without impressed magnetic field [2]. (The aspect ratio is $\Gamma=L / d$, where $L$ is the cell larger horizontal length, and $d$ the cell height.) We have observed the onset of convection for a critical Rayleigh

$\left({ }^{*}\right)$ Laboratoire associé au Centre National de la Recherche Scientifique. number $R=R_{\mathrm{c}}$, and the transition from steady twodimensional rolls to time dependent three-dimensional convection for $R=2.5 R_{\mathrm{c}}$ [3]. (The Rayleigh number is $R=\alpha g d^{3} \Delta T / v K$, where $\alpha$ is the isobaric thermal expansion coefficient, $g$ the acceleration of gravity, and $\Delta T$ the temperature difference across the cell.) This time-dependent motion, called by Busse the oscillatory instability [4], corresponds to a wave travelling in the direction of the roll axis, and consequently to a transverse time-dependent oscillation of the rolls. Its period corresponds to the characteristic circulation time of a roll, $d^{2} / K\left(d^{2} / K=11 \mathrm{~s}\right.$ for $d=0.7 \mathrm{~cm}$ ). When a magnetic field is applied parallel to the roll axis, the oscillatory instability becomes inhibited, releasing its energy into an increase of the roll circulation velocity. This is verified by an increase of the oscillatory instability frequency before its disappearance, and an increase of the effective conductivity. For a magnetic field perpendicular to the roll axis, the oscillatory instability is also inhibited, but its frequency is essentially unaffected and the effective conductivity unchanged. The released energy goes 
into joule heating due to the large eddy currents which are present in this case. Further increase of the magnetic field generates a new convective pattern, with twodimensional rolls parallel to the magnetic field direction. This last result is in agreement with the theoretical predictions of Chandrasekhar [1], and the experiments of Lehnert and Little [5]. Let us recall that experiments on the inhibition of convection by a vertical magnetic field have been performed by Nakagawa [6].

1. Experimental apparatus. - The experimental set-up, described in our previous article [2], has been modified in order to visualize the convective patterns [7]. The cell is a parallelepiped of aspect ratio $\Gamma=4$ $(L=2.8 \mathrm{~cm}, l=0.75 \mathrm{~cm}, d=0.7 \mathrm{~cm} ; L$ larger horizontal length of the cell, $l$ smaller horizontal length of the cell, $d$ cell height). The lateral boundaries are made of plexyglass. The bottom plate consists of a copper block. Under the top boundary made of sapphire, a layer of cholesteric liquid crystal visualizes the temperature profile due to hot ascending fluid and cold descending fluid (refer to Fig. 1). The heating and temperature regulation systems are described in our previous article [2]. For time-dependent measurements we use a small N.T.C. (negative temperature coefficient) thermistor placed in a $2 \mathrm{~mm}$ diameter hole drilled in the copper block. The temperature signal given by the bolometer is analysed by a 5420 Hewlett Packard digital signal analyser. An electromagnet provides a uniform horizontal magnetic field; the strength of the field could be varied up to 0.5 tesla.
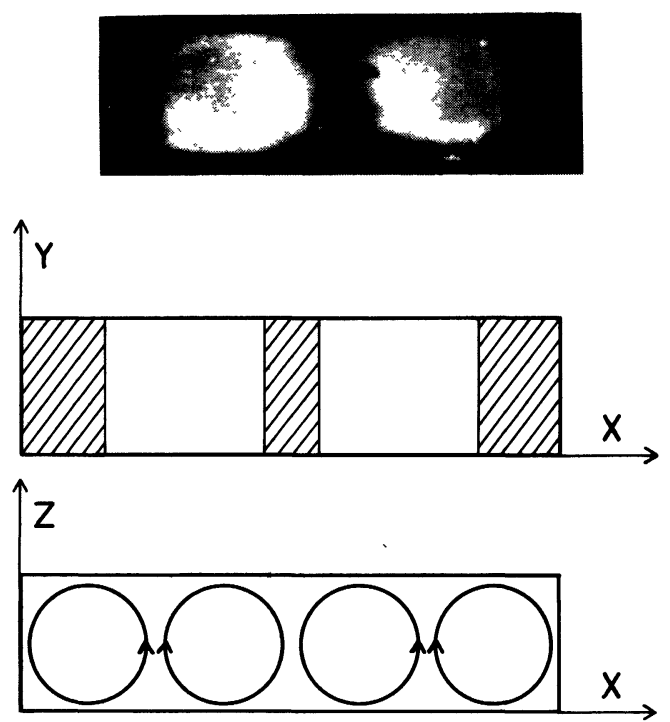

Fig. 1. - Photograph of the cholesteric liquid crystal layer seen from above, and qualitative sketch of the convective rolls. The bright regions correspond to hot ascending fluid, the dark regions to cold descending fluid.

2. Effect of the magnetic field. - The characteristic diffusion time scales are $d^{2} / v$ for vorticity, $d^{2} / K$ for heat, and $\mu_{0} \sigma d^{2}$ for magnetic field disturbances ( $\sigma$ is the electrical conductivity). For mercury at room temperature we have $d^{2} / v=890 \mathrm{~s}, d^{2} / K=22 \mathrm{~s}$, $\mu_{0} \sigma d^{2}=10^{-4} \mathrm{~s}$. The magnetic field diffusion time scale is the shortest. Thus, the magnetic field disturbances will not propagate as Alfven waves (see Ref. [1]). Besides, we deal with very low magnetic Reynolds numbers. Thus we can neglect the magnetic field due to eddy currents. Consequently, the magnetic field effect is only to add a term

$$
-\frac{\sigma B^{2}}{\rho} \Delta^{-1}\left(\frac{\partial^{2} v}{\partial x_{1}^{2}}\right)
$$

in the Navier-Stokes equation ( $\rho$ is the fluid density, $\Delta^{-1}$ represents the inverse of the Laplacian, $\mathbf{v}$ is the fluid velocity, and $x_{1}$ the direction of the magnetic field). This additional term represents some kind of anisotropic viscosity, inhibiting velocity variations along the magnetic field direction, and introduces a tendency towards two-dimensionality when it becomes more important than the velocity diffusion term $v \Delta \mathbf{v}\left(\right.$ i.e. when $\left.\frac{\sigma B^{2}}{\rho} \cdot \frac{d^{2}}{v} \gg 1\right)$.

3. Transverse magnetic field. - The dependence of the oscillatory instability amplitude and frequency on the magnetic field strength, in the case of a transverse magnetic field, is shown in figure 2 . With this geometry, the field acts along the $x$ axis and the oscillatory instability corresponds to a wave travelling in the $y$ direction. The magnetic field dependent term of the Navier-Stokes equation, $-\frac{\sigma B^{2}}{\rho} \Delta^{-1}\left(\frac{\partial^{2} v}{\partial x^{2}}\right)$, vanishes for a velocity which depends only on $y$; thus, the oscillatory instability frequency is almost unchanged. But the velocity amplitude, which depends

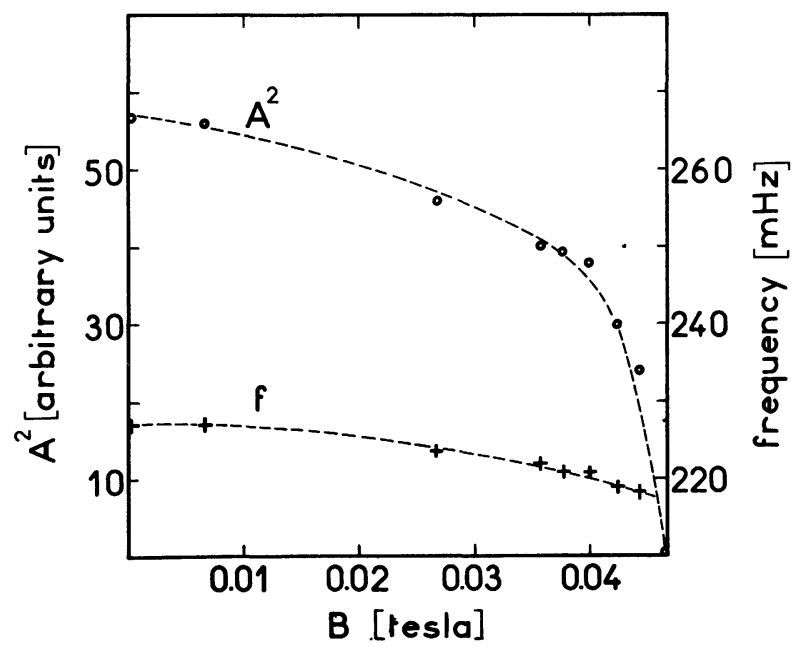

Fig. 2. - The dependence of the oscillatory instability amplitude and frequency on the magnetic field strength. The magnetic field direction is perpendicular to the roll axis. $A$ is the oscillatory instability amplitude, in arbitrary units. 
on $x$, is affected by the magnetic field, and decreases. The circulation time of convective rolls increases and consequently the oscillatory instability frequency slightly decreases. An equivalent point of view is to notice that a transverse field induces closed patterns of large eddy currents. The potential energy released by the buoyancy force must balance the energy dissipated by both viscosity and joule heating. Consequently, the field inhibits convective motions.

4. Longitudinal magnetic field. - When the magnetic field is parallel to the roll axis, it mainly affects

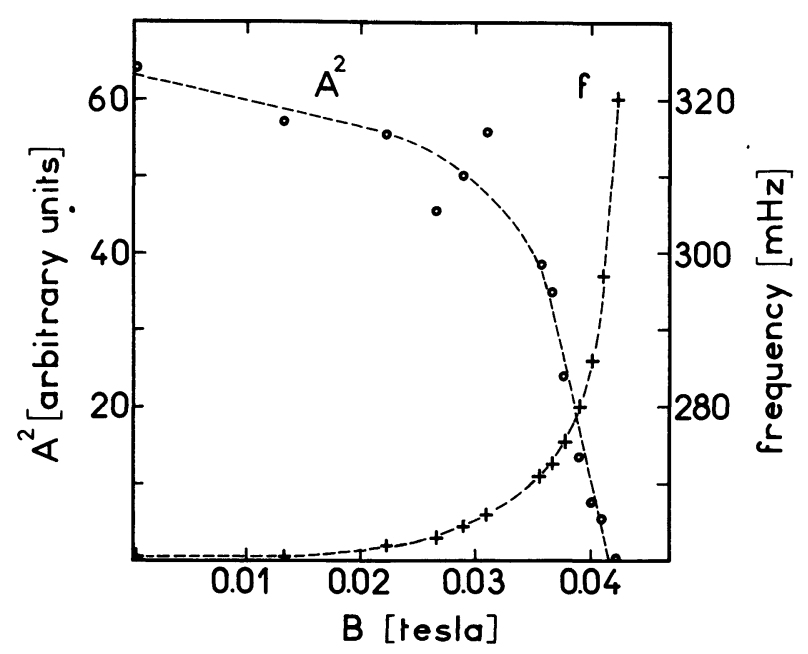

Fig. 3. - The dependence of the oscillatory instability amplitude and frequency on the magnetic field strength. The magnetic field direction is parallel to the roll axis. the transverse oscillations of the rolls. As shown in figure 3 , the oscillatory instability amplitude vanishes as the field is increased, and convection becomes steady and bidimensional if we neglect the velocity variations due to the lateral boundaries perpendicular to the field direction. In a bidimensional convection, $(\partial \mathbf{v} / \partial y=0)$, there are no electromagnetic forces and no joule dissipation. Thus the kinetic energy associated with oscillatory motion is transferred to convective bidimensional motion, and the convective velocity is increased. Consequently, before the complete attenuation of the oscillatory instability, we observe its frequency increase (refer to Fig. 3). The convective velocity increase is in good agreement with the observed effective conductivity increase (i.e. with the Nusselt number increase).

5. Conclusion. - As theoretically predicted, a horizontal uniform magnetic field, applied along the roll axis, delayed the onset of the oscillatory instability by inhibiting three-dimensional motions, and increases the effective conductivity of the convective fluid. This higher heat transport may correspond to an inertial convection mode [8]. Besides, we expect that experiments with a magnetic field will allow us to observe new scenarios in the transition to weak turbulence. At low magnetic field values, its main effect is to add an additional damping term to the oscillators. This could affect the various period multiplication bifurcations to turbulence. At very high field values, by inhibiting any oscillatory instabilities, it may lead to new degrees of freedom in the bifurcation leading to turbulence.

References

[1] Chandrasekhar, S., Hydrodynamic and hydromagnetic stability (Oxford, Clarendon Press) 1961.

[2] Fauve, S., Libchaber, A., Int. Conf. on synergetics, SchloszElmau, (1981). To be published (Springer Verlag).

[3] Previous experiments of thermal convection in mercury have been performed by : RossBy, H. T., J. Fluid Mech. 36 (1969) 309
[4] Busse, F. H., J. Fluid Mech. 52 (1972) 97.

[5] Lehnert, B., LitTle, N. C., Tellus 9 (1957) 97.

[6] Nakagawa, Y., Proc. R. Soc. A 240 (1957) 108 ; Proc. R. Soc. A 249 (1959) 138.

[7] LAROCHE, C., private communication, and to be published.

[8] Proctor, M. R. E., J. Fluid. Mech. 82 (1977) 97. Busse, F. H., Clever, R. M., J. Fluid Mech. 102 (1981) 75.

KrishnamuRTI, R., J. Fluid Mech. 60 (1973) 285. 